\title{
Parental and Adult Attachment and Eating Symptomology in Eating Disorder Patients and Sine Morbo Individuals
}

\author{
Tamás Dömötör Szalai M.A. ${ }^{1}$, Edit Czeglédi M.A., Ph.D. ${ }^{1}$ \\ ${ }^{1}$ Institute of Behavioural Sciences, Semmelweis University, Institute of Behavioural Sciences, Hungary \\ Correspondence: Tamás Dömötör Szalai, Institute of Behavioural Sciences, Semmelweis University, Budapest, \\ Nagyvárad tér 4., 1089 Hungary.
}

Received: April 1, 2017

doi:10.11114/ijsss.v5i6.2420
Accepted: May 10, $2017 \quad$ Available online: May 13, 2017

URL: https://doi.org/10.11114/ijsss.v5i6.2420

\begin{abstract}
Attachment can contribute to eating disorder symptomology through various paths, including emotion regulation. However, the relationship between parental and adult attachment and emotional eating and other eating disorder symptoms have been barely investigated on comparative samples. This cross-sectional, questionnaire-based online survey aimed to assess the relationship between parental and adult attachment qualities with the eating behavior severity, emotional eating, and the le vel of depression in 67 female anorexia nervosa, bulimia nervosa, and binge eating disorder patients, compared to 67 female sine morbo individuals. Eating disorder patients less frequently had secure attachment, and were more often fearful or preoccupied than sine morbo individuals. In sine morbo individuals lower adult attachment security, but in patients, lower parental care was related to eating disorder symptoms. In sine morbo individuals, higher preoccupation, but in patients, higher fearfulness and lower care was related to emotional eating. Lower attachment security $(\mathrm{OR}=0.54)$, younger age $(\mathrm{OR}=0.93)$ and higher depression $(\mathrm{OR}=1.04)$ explained $36.6 \%$ of the variance of diagnosed eating disorders. A complex interplay could be highlighted between dysfunctional attachment dimensions and eating symptomology in both groups - but with different patterns. Perceived parental care may be influential for eating disorder patients, whilst the degree of adult attachment security can be influential for sine morbo individuals. Lower attachment security was a predictor of eating disorders, which suggests the protective value of enhancing attachment security. However, further attachment-based interventions are required.
\end{abstract}

Keywords: parental bonding, adult attachment, eating disorder, emotional eating

\section{Introduction}

Attachment is the primary affectional bond between the child and his or her caregiver; as an evolutionarily grounded motivational-behavioral system, attachment serves the physical and psychological safety of the child (Ainsworth, 1989). Its 'Internal Working Model' (IWM; Bowlby, 1977) contains complex representations of the self and the object that may extend to significant others, most of all to fathers (Buist et al., 2002). Attachment patterns can be characterized by the underlying dimensions of anxiety and avoidance, and different concepts of self and others (Griffin \& Bartholomew, 1994; Mikulincer et al., 2003). These patterns can be modified; however, they are mostly stable throughout the lifespan (Pinquart et al., 2013). They contribute to emotions, cognitions and interpersonal behavior, influencing personality development as well as relationship dynamics (Beeney, 2015). Through abnormal transitions between developmental phases and interactions with environmental and temperamental factors, dysfunctional attachment patterns can contribute to abnormal personality functioning and increase the vulnerability for psychopathological symptoms (Lenkiewicz et al., 2015; Mikulincer \& Shaver, 2012).

\subsection{Attachment and Eating Disorders}

Attachment disturbances have been linked with eating disorders (EDs) (Illing et al., 2010). Regarding parental bonding, eating disorder (ED) patients experience less cohesive and supportive family structure (Latzer et al., 2002), as well as stronger separation anxiety and more insecure attachment than sine morbo (SM; ones with no ED symptoms) individuals (Kuipers et al., 2016). Mothers of SM ones reported higher security than mothers of anorexic patients, and were less avoidant than mothers of bulimic patients (Tereno et al., 2008). The quality of parental attachment can lead to dysfunctional eating attitudes; it may influence the quantity and quality of food eaten and moderate the risk of EDs (Faber \& Dubé, 2015; Milan \& Acker, 2014). From the opposite direction of influence, both the physical and 
psychological proximity needs can be increased in patients after the onset of EDs. ED symptoms challenge the family's attention and generally narrow the proximity between the patients and their parents (Orzolek-Kronner, 2002). While eating and body concerns distract patients' attention from their parental bonding problems, suggesting hidden interpersonal needs and strong attachment dynamics in the background of the more apparent ED symptomology (Latzer et al., 2002; Orzolek-Kronner, 2002).

Adult attachment concerns in EDs are still predominantly unresolved, especially in cases with comorbid mood or personality disorders (Gander et al., 2015). Among other factors, bulimic symptoms and body dissatisfaction are related to attachment insecurity accompanied by ambivalent or fearful relationships (Elgin \& Pritchard 2006; Ringer \& Crittenden, 2007). In cases of bulimia, preoccupied attachment may be predominant, while in anorexia dismissive attachment may predominate (Ringer \& Crittenden, 2007; Zachrisson \& Skårderud, 2010). However, specific relationships between attachment patterns and subgroups of eating symptomology are inconsistent (Gander et al., 2015).

Some results suggest that attachment quality may be related to the type of symptoms rather than to the type of diagnosis, as binge and purge anorexics show stronger avoidance and higher anxiety than bulimics or restrictive anorexics (Illing et al., 2010). Thus, diverse attachment concerns can be related to restrictive or binge and purge symptoms, highlighting a scope of research that should be furthered. The severity of symptoms can also be more strongly associated with attachment than the type of ED (O'Shaughnessy \& Dallos, 2009); while the intensity of ED symptomology can be dependent on the degree of attachment insecurity (Broberg et al., 2001), suggesting careful, supportive parenting and the degree of adult attachment security as central traits of diverse findings.

\subsection{Attachment, Emotion Regulation and Emotional Eating}

The relationship between attachment and ED symptoms can be rather complex mediated by several factors (Tasca \& Balfour, 2014), including negative moods and emotion regulation (Tasca et al., 2009a), suggesting to take the level of negative moods into account when investigating the relationship between attachment and EDs. Mood states can strongly contribute to eating behavior and to the quantity of food eaten (Geliebter \& Aversa, 2003). Attachment disturbances negatively influence stress-sensitivity (Maunder \& Hunter, 2008) and can contribute to distressful and depressive mood states (Tasca et al., 2009a; Van Durme et al., 2015). Based on different distress-reducing strategies such as hyperactivation or deactivation of emotions attachment dysfunctions can increase the degree of impulsivity (Fossati et al., 2005; Van Durme et al., 2015) and impair creative coping mechanisms (Mikulincer et al. 2003), resulting in maladaptive emotion regulating actions including maladaptive eating (Ty \& Francis, 2013).

In spite of this, hardly any studies have investigated the relationship between attachment and emotional eating (Hernandez-Hons \& Wooley, 2011), which is defined as eating as a maladaptive coping response in order to reduce negative emotions such as anger, frustration loneliness or depression (Geliebter \& Aversa, 2003; Masheb \& Grilo, 2006). However, both actual parental attachment in children and recalled one in adults predicted the extent of high-caloric food consumption (Faber \& Dubé, 2015). Although emotional eating is not a clinically significant ED, but it is associated with higher food intake (Turner et al., 2010), increasing body mass index (Anglé et al., 2009), compensatory dietary habits (Nguyen-Michel et al., 2007), and it can moderate the association between daily hassles and uncontrolled eating (O'Connor et al., 2008). Therefore, investigating the relationship between attachment characteristics and emotional eating may be highly relevant in understanding a wide-spread maladaptive eating behavior of SM individuals and a potential risk factor of diagnosed EDs.

On the basis of these findings, the relationship between parental adult attachment characteristics and the severity of maladaptive eating behaviors including emotional eating, and binge and purge symptoms shall be investigated within a framework of complex symptoms in both ED and SM indi viduals (Polivy \& Herman, 2002; Pace et al., 2016; Tereno et al., 2008). Since the extent of attachment's contribution on diagnosed EDs varies across studies, this aspect shall also be examined, especially in Eastern and Central European regions, where related data are lacking.

\subsection{Aims and Hypotheses}

The aim of this study was to test the relationship between parental and adult attachment characteristics and ED symptoms in ED patients and SM individuals, and to test attachment security as a predictor of diagnosed EDs. It was hypothesized that

1. Insecure adult attachment types would be more frequent in ED patients than in SM individuals;

2. The degree of attachment insecurity would be positively related to the severity of drive for thinness, body dissatisfaction, tendencies for emotional eating, bulimia, and binge and purge symptoms; and

3. Higher attachment security is a protective factor against diagnosed EDs. 


\section{Method}

\subsection{Participants}

Data were gathered from 176 participants. Male respondents $(N=10)$, one respondent with lacking data on body weight, two respondents with no ED diagnosis, but lower BMI than 17.5, as well as fifteen participants with previous ED treatment, but no current diagnosis or treatment and normal BMI were deleted to prevent distorting effects. As the continuum hypothesis of EDs involves obesity (VanderHam et al., 1997), and emotional eating can be related to obesity and disordered eating (Czeglédi \& Urbán, 2010), 14 overweight (BMI $\geq 25$ ) emotional eaters (TFEQ-R21 Emotional Eating Scale $\geq 3$ points) were also excluded.

The final sample consisted of 134 females. Mean age was 29.9 years $(S D=10.43$ years, range: $13-58$ years). Mean BMI was $23.4(S D=6.23$, range: $12.3-44.8)$. According to the WHO (2000) criteria, $28.4 \%$ of the final sample were underweight $(\mathrm{BMI}<18.5), 46.3 \%$ had normal weight $(\mathrm{BMI}=18.5-24.9), 13.4 \%$ were overweight $(\mathrm{BMI}=25.0-29.9)$, and $11.9 \%$ were obese (BMI $\geq 30$ ). Altogether, $65.7 \%$ of the respondents lived in Budapest, with $27.6 \%$ living in towns and $6.7 \%$ in villages. Only $17.2 \%$ of the respondents had elementary level education; $31.3 \%$ finished secondary school and $51.5 \%$ had higher education. The majority (56.7\%) of participants was single, $18.7 \%$ were in relationships, $20.9 \%$ were married, and $3.7 \%$ were divorced. The sample consisted of two groups:

- The eating disorder (ED) group involved $67 \mathrm{ED}$ patients (50.0\%). Inclusion criteria included the following DSM-V diagnoses (APA, 2013) by senior psychiatrists or clinical psychologists: anorexia nervosa $(N=14)$; bulimia nervosa $(N=14)$; binge eating disorder $(\mathrm{BED})(N=5)$; or ED not otherwise specified $(N=9)$. Further criteria included former ED diagnosis and treatment with a current BMI lower than $17.5(N=9)$, or clinically significant binge or bulimic symptoms measured on the EDI and on the EBSS $(N=18)$.

- The sine morbo (SM) group consisted of 67 participants (50.0\%), who received neither former nor present ED diagnosis or treatment; had a BMI above 17.5; scored less than 14 on the Bulimia Subscale on the EDI; and scored less than 3 points on the Emotional Eating Subscale of the TFEQ-R21.

\subsection{Measures}

Sociodemographic and anthropometric data. Data were gathered on age, residence, educational level, self-reported weight $(\mathrm{kg})$ and height $(\mathrm{cm})$. BMI $(\mathrm{kg} / \mathrm{m} 2)$ was also calculated.

Eating Disorder Inventory (EDI). The EDI (Garner et al., 1983; Túry \& Szabó, 2000) is the most often used multidimensional measure that assesses classic EDs and psychological characteristics of anorexia nervosa with 64 items divided into eight subscales. In the present analysis, three scales were included. The Drive for Thinness Subscale measures excessive dietary concerns, preoccupation with body weight, fears of gaining weight and entrenchment in thinness. The Body Dissatisfaction Subscale reflects beliefs that certain body parts are fat and require shape modification. The Bulimia Subscale assesses the tendency for uncontrollable overeating (binging) and purging. Each item is rated on a 6-point Likert-type scale ranging from 1 (never) to 6 (always). Higher scores reflect more pathologic eating and body concerns. The cutoff point is 14 points for Drive for Thinness, 14 points for Bulimia, and 21 points for Body Dissatisfaction. Cronbach's $\alpha$ coefficient of Drive for Thinness was .92, .91 for Bulimia, and .78 for Body Dissatisfaction.

Eating Behavior Severity Scale (EBSS). The EBSS (Yager et al., 1987; Túry \& Szabó, 2000) is a 7 -item inventory that assesses the frequency of binges, use of purgatives, diuretics, vomiting, dieting, and exercise on a 7 -point Likert-type scale from 0 (never) to 6 (several times daily) during the last three months. Cronbach's $\alpha$ coefficient of the scale was .56, perhaps on account of the heterogeneity of symptoms measured.

Three-Factor Eating Questionnaire - Revised 21-items (TFEQ-R21). The TFEQ-R21 (Tholin et al., 2005; Czeglédi \& Urbán, 2010) assesses cognitive restraint, uncontrolled eating and emotional eating. In this study the Emotional Eating Scale was used to assess the disposition to overeat when feeling anxious, depressed or lonely. The scale consists of 6 items rated on a 4-point Likert-type scale from 1 (definitely true) to 4 (definitely false); higher scores reflect a higher propensity for emotional eating. Item scores were averaged, and the cut-off for emotional eating was defined at 3 points. The scale's Cronbach's $\alpha$ coefficient was 94.

Relationship Scales Questionnaire (RSQ). The RSQ (Griffin \& Bartholomew, 1994; Demetrovics, 2007) is the most widely-used measure of the four categories of adult attachment. From its 30 items, five-five contribute to Secure and Dismissive scales and four-four to Fearful and Preoccupied scales. Items are rated on a 5-point Likert-type scale from 1 (not at all like me) to 5 (very much like me). The RSQ was designed as a continuous measure, so attachment dimensions are mainly assessed. Respondents can be classified into patterns based on the highest standard scores. Although the RSQ has relatively low internal consistency; it could be regarded as a valid instrument with practical benefits (Ravitz et al., 2010). Cronbach's $\alpha$ coefficient of the secure scale was .34, thus and item selection was conducted. When item 10 ( $I$ am comfortable depending on other people) was deleted, Cronbach's $\alpha$ coefficient increased to .48; thus the 4-item scale 
was used in the analyses. Cronbach's $\alpha$ coefficient was .69 for fearful attachment, .45 for preoccupied attachment, and .58 for dismissive attachment.

Parental Bonding Instrument (PBI). The PBI (Parker et al., 1979; Tóth \& Gervai, 1999) is a 25-item self-report questionnaire that measures the quality of paternal and maternal bonding during the first 16 years of life with two bipolar scales: (a) Parental care assesses how much care or indifference the child was given; and (b) Overprotection measures assess how overprotective or autonomous parenting was. Items are rated on a 4-point Likert-type scale from 0 (very unlike me) to 3 (very like me). Cronbach's $\alpha$ coefficient was .94 for maternal care, .95 for paternal care, .91 for maternal overprotection, and .90 for paternal overprotection.

Center for Epidemiologic Studies Depression Scale (CES-D). The CES-D (Radloff, 1977; Demetrovics, 2007) is a 20-item self-report measure that assesses the intensity of cognitive, affective, behavioral and interpersonal symptoms of depression over the last week on a 4-point Likert scale, from 0 (seldom or never) to 3 (very often or always). Cronbach's $\alpha$ coefficient of this scale was .93.

\subsection{Procedure}

This cross-sectional, questionnaire-based online survey was carried out from April 2015 until July 2016. Participation was voluntary and was not compensated in any way; all participants had given their informed consent to be involved in the study before filling out the survey. Ethical approval was given by the Medical Research Council Scientific and Research Committee (5692-2/2015/EKU). A convenience sampling method was used. The SM group received the survey through uni versity email systems (two in the capital and one in the southern region of the country) and social media surfaces. ED patients received the survey after completing DSM-V (APA, 2013) diagnostic interviews with senior psychiatrists or clinical psychologists, but before entering treatment. Exact non-response rates were not available from the SM group, but according to clinician reports, less than one third of the invited patients filled out the survey.

\section{Results}

\subsection{Statistical Analyses}

In order to estimate the scales' internal consistency, Cronbach's $\alpha$ coefficient was calculated. The distribution of the variables was controlled with histograms. In case any of the compared variables had not shown normal distribution according to the skewness or kurtosis of the histogram, automatically nonparametric analyses were used ( $\mathrm{Z}$ values in Table 1, and Table 3 completely). Descriptive statistics were applied to compute means, standard de viations and Spearman's rank correlation and partial rank correlations of the variables. The interpretation of the correlation coefficients' value was based on Cohen's (1988) definition: weak below .3, moderate from .3 to .5 , strong for .5 and above. Differences of partial Spearman's rank correlation coefficients were calculated with Fisher's z' transformation. Independent-samples $t$-test was used to compare ED and SM groups, when the distribution was impaired the Mann-Whitney $U$-test was applied. The effect sizes were estimated with Cohen's $d$; small effect size is 0.20 , medium effect size is 0.50 and large effect size is above 0.80 (Cohen, 1988). Chi-square tests with Cramer's V value were applied to compare the frequencies of attachment patterns between the two groups. Predictors of EDs were tested with hierarchical binary regression analysis with the enter method. Analyses were performed with the IBM SPSS 23.0 (IBM Corporation, 2015) and the ROPstat (Vargha et al., 2015) statistical packages.

\subsection{Comparisons of the Groups}

According to the results of the independent-samples $t$-test and the Mann-Whitney $U$-test, the ED group was significantly younger, had a lower BMI, with a higher prevalence of being underweight. Regarding ED symptoms, the ED group had three times more intensive drive for thinness, twice as severe body dissatisfaction, three times stronger bulimic symptoms, significantly stronger tendencies for emotional eating, and higher levels of depression than SM individuals. Regarding attachment, the ED group had significantly less secure adult attachment, more preoccupied or fearful attachments, and a tendency towards a higher level of maternal overprotection. Results are detailed in Table 1. 
Table 1. Descriptive statistics and comparisons of the groups

\begin{tabular}{|c|c|c|c|}
\hline Variables & $\begin{array}{l}\text { SM group } \\
(N=67)\end{array}$ & $\begin{array}{l}\text { ED group } \\
(N=67)\end{array}$ & Comparis on of the groups \\
\hline Age Mean (SD) & 33.5 (10.24) & $26.3(9.39)$ & $\begin{array}{l}\mathrm{t}(132)=4.211^{* * *} \\
(\text { Cohen's } d=0.73)\end{array}$ \\
\hline BMI Mean (SD) & $23.9(5.63)$ & $20.8(6.45)$ & $\begin{array}{l}\mathrm{t}(132)=2.943 * * \\
(\text { Cohen's } d=0.51)\end{array}$ \\
\hline BMI category & $7(10.4 \%)$ & $31(46.3 \%)$ & $\chi^{2}(3)=22.842 * * *$ \\
\hline normal weight & $39(58.2 \%)$ & $23(34.3 \%)$ & (Cramer's V $=.413$ ) \\
\hline $\begin{array}{ll}\mathrm{N}(\%) & \begin{array}{l}\text { overweight } \\
\text { obese }\end{array}\end{array}$ & $\begin{array}{l}13(19.4 \%) \\
8(11.9 \%)\end{array}$ & $\begin{array}{l}5(7.5 \%) \\
8(11.9 \%)\end{array}$ & \\
\hline Drive for thinness (EDI) Mean (SD) & $4.8(5.77)$ & $12.4(6.28)$ & $\begin{array}{l}\mathrm{Z}=-6.263 * * * \\
(\text { Cohen's } d=-1.27)\end{array}$ \\
\hline Body dissatisfaction (EDI) Mean (SD) & $7.5(7.29)$ & $13.6(7.41)$ & $\begin{array}{l}\mathrm{Z}=-4.501 * * * \\
(\text { Cohen's } d=-0.82)\end{array}$ \\
\hline Bulimic symptoms (EDI) Mean (SD) & $1.4(2.38)$ & $5.3(5.60)$ & $\begin{array}{l}\mathrm{Z}=-4.505 * * * \\
(\text { Cohen's } d=-0.89)\end{array}$ \\
\hline Emotional Eating (TFEQ-R21) & $1.9(0.73)$ & $2.3(1.00)$ & $\begin{array}{l}\mathrm{Z}=-2.282^{*} \\
(\text { Cohen's } d=-0.44)\end{array}$ \\
\hline Secure attachment (RSQ) Mean (SD) & $3.2(0.77)$ & $2.6(0.77)$ & $\begin{array}{l}\mathrm{t}(132)=5.103^{* * *} \\
(\text { Cohen's } d=0.88)\end{array}$ \\
\hline Fearful attachment (RSQ) Mean (SD) & $2.9(1.01)$ & $3.4(0.91)$ & $\begin{array}{l}\mathrm{t}(132)=-3.205^{* *} \\
(\text { Cohen's } d=-0.55)\end{array}$ \\
\hline Preoccupied attachment (RSQ) Mean (SD) & $3.1(0.67)$ & $3.4(0.84)$ & $\begin{array}{l}\mathrm{t}(132)=-2.155^{*} \\
(\text { Cohen's } d=-0.37)\end{array}$ \\
\hline Dismissive attachment (RSQ) Mean (SD) & $3.42(0.70)$ & $3.52(0.70)$ & $\begin{array}{l}\mathrm{t}(132)=-0.889 \\
(\text { Cohen's } d=-0.15)\end{array}$ \\
\hline Maternal care (PBI) Mean (SD) & $25.7(8.64)$ & $25.0(9.06)$ & $\begin{array}{l}\mathrm{Z}=0.412 \\
(\text { Cohen's } d=0.09)\end{array}$ \\
\hline Paternal care (PBI) Mean (SD) & $20.3(10.06)$ & $18.4(10.40)$ & $\begin{array}{l}\mathrm{t}(132)=1.039 \\
(\text { Cohen's } d=0.18)\end{array}$ \\
\hline Maternal overprotection (PBI) Mean (SD) & $13.6(7.53)$ & $16.2(9.39)$ & $\begin{array}{l}\mathrm{t}(126.1)=-1.816^{+} \\
(\text {Cohen's } d=-0.31)\end{array}$ \\
\hline Paternal overprotection (PBI) Mean (SD) & $12.2(7.97)$ & $13.2(8.88)$ & $\begin{array}{l}\mathrm{t}(132)=-0.727 \\
(\text { Cohen's } d=-0.13)\end{array}$ \\
\hline Depression (CES-D) Mean (SD) & $16.3(11.34)$ & $26.7(12.42)$ & $\begin{array}{l}\mathrm{t}(132)=-5.054 * * * \\
(\text { Cohen's } d=-0.87)\end{array}$ \\
\hline
\end{tabular}

Note. ${ }^{+} p<.10 . * * p<.01 . * * * p<.001$. SM: sine morbo group, ED: eating disorder group. The 4-item version of the RSQ security scale was used to assess secure adult attachment.

Altogether, $30.6 \%$ of all respondents had secure, $26.9 \%$ had fearful, $26.9 \%$ had preoccupied, and $15.7 \%$ had dismissive adult attachment patterns. According to the results of the Chi-square test, the frequency of attachment patterns was significantly different between the groups $\left(\chi^{2}(3)=16.408, p=.001\right.$, Cramer's $\left.\mathrm{V}=.350, p=.001\right)$. The SM group had predominantly secure attachment patterns $(44.8 \%)$, which was present in only $16.4 \%$ of the patient group. Preoccupied attachment patterns were almost three times more prevalent in the ED group (38.8\%) than in the SM group (14.9\%). Results are detailed in Figure 1. 


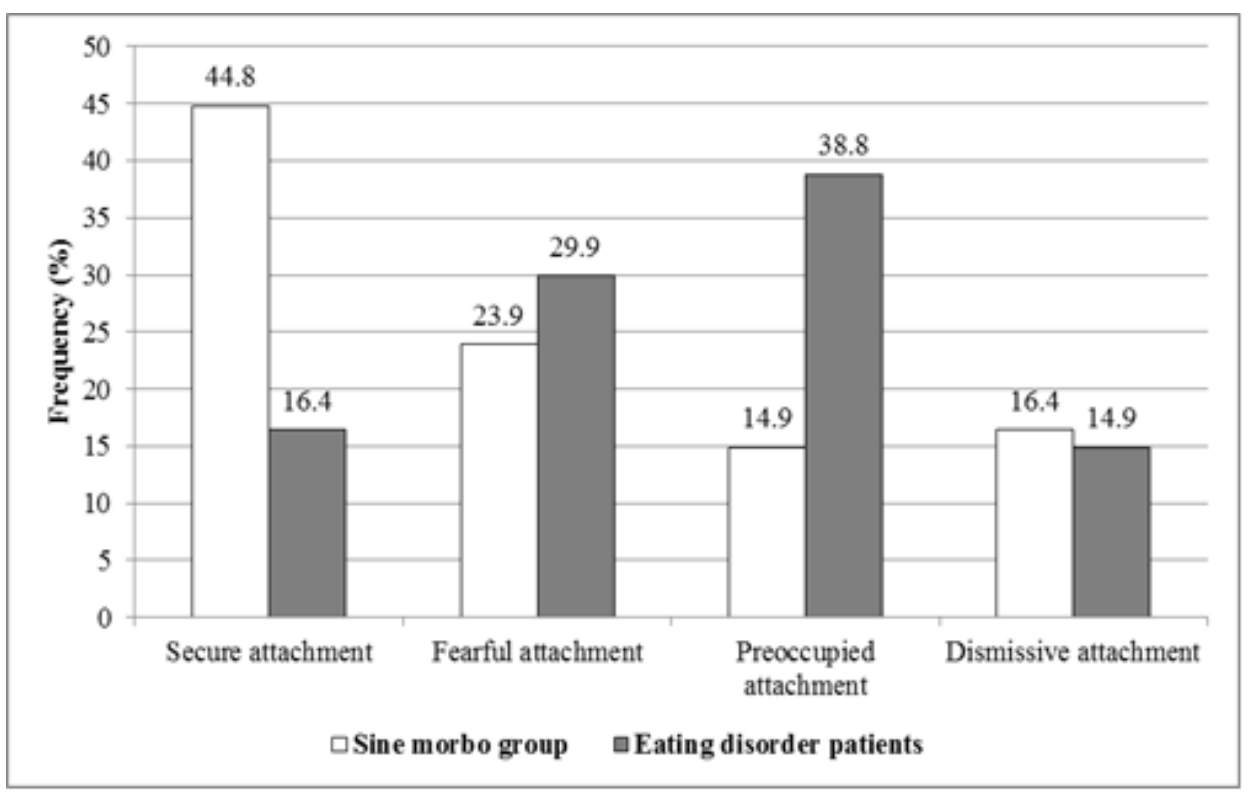

Figure 1. The frequency of adult attachment patterns in eating disorder patients and sine morbo individuals

Note. $N$ eating disorder group $=67, N$ sine morbo group $=67$.

Collectively, $70.1 \%$ of the SM group and $77.6 \%$ of the ED group dieted at least monthly, and $77.6 \%$ of both groups exercised at least monthly to reduce weight. Appetite suppressors were used by $4.4 \%$ of the SM group and $11.9 \%$ of the ED group. Altogether, $34.3 \%$ of the SM group reported at least monthly binges, and $62.7 \%$ of the ED group reported binging with at least monthly frequency. One third (32.8\%) of the ED group reported at least monthly self-induced vomiting, with only $3 \%$ of the SM group reporting the same. Purgatives were used at least monthly by $7.5 \%$ of the SM group and $22.4 \%$ of the ED group; diuretics were used at least monthly by 3\% of the SM group and 6\% of the ED group. In order to measure the presence of purging, the use of purgatives, diuretics and self-induced vomiting were united with simple summation. Results are detailed in Table 2.

Table 2. The severity of maladaptive eating behaviors in eating disorder patients and sine morbo individuals

\begin{tabular}{|c|c|c|c|c|c|c|c|c|}
\hline & Variable & Never & Monthly once & $\begin{array}{l}\text { Several } \\
\text { times } \\
\text { monthly }\end{array}$ & Weekly once & $\begin{array}{l}\text { Several } \\
\text { times } \\
\text { weekly }\end{array}$ & Daily & $\begin{array}{l}\text { Several } \\
\text { times daily }\end{array}$ \\
\hline \multirow[t]{11}{*}{ SM } & Dieting & $\begin{array}{l}20 \\
(29.9 \%)\end{array}$ & $\begin{array}{l}16 \\
(23.9 \%)\end{array}$ & $\begin{array}{l}8 \\
(11.9 \%)\end{array}$ & $\begin{array}{l}4 \\
(6.0 \%)\end{array}$ & $\begin{array}{l}9 \\
(13.4 \%)\end{array}$ & $\begin{array}{l}5 \\
(7.5 \%)\end{array}$ & $\begin{array}{l}5 \\
(7.5 \%)\end{array}$ \\
\hline & Exercises & $\begin{array}{l}15 \\
(22.4 \%)\end{array}$ & $\begin{array}{l}5 \\
(7.5 \%)\end{array}$ & $\begin{array}{l}5 \\
(7.5 \%)\end{array}$ & $\begin{array}{l}13 \\
(19.4 \%)\end{array}$ & $\begin{array}{l}21 \\
(31.3 \%)\end{array}$ & $\begin{array}{l}7 \\
(10.4 \%)\end{array}$ & $\begin{array}{l}1 \\
(1.5 \%)\end{array}$ \\
\hline & Appetite & 64 & 1 & 1 & 1 & 0 & & \\
\hline & suppressors & $(95.5 \%)$ & $(1.5 \%)$ & $(1.5 \%)$ & $(1.5 \%)$ & $(0.0 \%)$ & $(0.0 \%)$ & $(0.0 \%)$ \\
\hline & Binge eating & & & 3 & 2 & 5 & & \\
\hline & & $(65.7 \%)$ & $(17.9 \%)$ & $(4.5 \%)$ & $(3.0 \%)$ & $(7.5 \%)$ & $(1.5 \%)$ & $(0.0 \%)$ \\
\hline & Vomiting & & & & 0 & & & \\
\hline & & $(97.0 \%)$ & $(1.5 \%)$ & $(0.0 \%)$ & $(0.0 \%)$ & $(1.5 \%)$ & $(0.0 \%)$ & $(0.0 \%)$ \\
\hline & Purgatives & 62 & 2 & 2 & 0 & 0 & 0 & 1 \\
\hline & Diuretics & & $(3.0 \%)$ & $(3.0 \%)$ & $(0.0 \%)$ & $(0.0 \%)$ & $(0.0 \%)$ & $(1.5 \%)$ \\
\hline & & $(97.0 \%)$ & $(0.0 \%)$ & $(1.5 \%)$ & $\begin{array}{l}0 \\
(0.0 \%)\end{array}$ & $(1.5 \%)$ & $(0.0 \%)$ & $(0.0 \%)$ \\
\hline \multirow[t]{12}{*}{ ED } & Dieting & $\begin{array}{l}15 \\
(22.4 \%)\end{array}$ & $\begin{array}{l}4 \\
(6.0 \%)\end{array}$ & $\begin{array}{l}6 \\
(9.0 \%)\end{array}$ & $\begin{array}{l}5 \\
(7.5 \%)\end{array}$ & $\begin{array}{l}10 \\
(14.9 \%)\end{array}$ & $\begin{array}{l}12 \\
(17.9 \%)\end{array}$ & $\begin{array}{l}15 \\
(22.4 \%)\end{array}$ \\
\hline & Exercises & 15 & 6 & 6 & 7 & 17 & 12 & 4 \\
\hline & & $(22.4 \%)$ & $(9.0 \%)$ & $(9.0 \%)$ & $(10.4 \%)$ & $(25.4 \%)$ & $(17.9 \%)$ & $(6.0 \%)$ \\
\hline & Appetite & & 5 & & & & & \\
\hline & suppressors & $(88.1 \%)$ & $(7.5 \%)$ & $(1.5 \%)$ & $(0.0 \%)$ & $(0.0 \%)$ & $(1.5 \%)$ & $(1.5 \%)$ \\
\hline & Binge eating & $\begin{array}{l}25 \\
(37.3 \%)\end{array}$ & $\begin{array}{l}5 \\
(7.5 \%)\end{array}$ & $\begin{array}{l}5 \\
(7.5 \%)\end{array}$ & $\begin{array}{l}3 \\
(4.5 \%)\end{array}$ & $\begin{array}{l}16 \\
(23.9 \%)\end{array}$ & $\begin{array}{l}7 \\
(10.4 \%)\end{array}$ & $\begin{array}{l}6 \\
(9.0 \%)\end{array}$ \\
\hline & Vomiting & 45 & 4 & 1 & 2 & 7 & 2 & 6 \\
\hline & & $(67.2 \%)$ & $(6.0 \%)$ & $(1.5 \%)$ & $(3.0 \%)$ & $(10.4 \%)$ & $(3.0 \%)$ & $(9.0 \%)$ \\
\hline & Purgatives & & & & & & & \\
\hline & & $(77.6 \%)$ & $(9.0 \%)$ & $(3.0 \%)$ & $(3.0 \%)$ & $(3.0 \%)$ & $(3.0 \%)$ & $(1.5 \%)$ \\
\hline & Diuretics & 63 & 0 & 2 & 1 & 1 & 0 & \\
\hline & & $(94.0 \%)$ & $(0.0 \%)$ & $(3.0 \%)$ & $(1.5 \%)$ & $(1.5 \%)$ & $(0.0 \%)$ & $(0.0 \%)$ \\
\hline
\end{tabular}

Note. $N$ eating disorder $=67, N$ sine morbo $=67$. SM: sine morbo group, ED: eating disorder group. Symptoms were measured by the EBSS. 
According to the results of the Spearman's rank correlation analysis in the SM group, significant negative and moderate associations were found between attachment security and drive for thinness, bulimic tendencies, binges, and dieting. While significant negative, however statistically weak associations appeared between attachment security, body dissatisfaction and exercise. Adult attachment fearfulness showed a significant positive and moderate relationship with drive for thinness, and significant, positive, however weak relationships with body dissatisfaction, bulimic tendencies and binges. Adult attachment preoccupation showed a significant positive but weak correlation with drive for thinness and emotional eating. The degree of dismissal showed a significant positive and moderately strong association with exercise for weight loss. Lower maternal care showed a significant—but weak-relationship to higher drive for thinness and more frequent dieting.

In the ED group, significantly positive and statistically weak associations were found between attachment fearfulness and drive for thinness; emotional eating, binges, and purging; and between paternal overprotection and emotional eating. Both maternal and paternal care significantly and negatively correlated with bulimia, emotional eating, and binge and purge behaviors. Associations were statistically moderate, except for the weak relationships between maternal care, emotional eating and binges. Tendency-level, positive correlation was found between dismissive attachment and purging, and tendency-level negative correlation was present between maternal care and dieting. Results are detailed in Table 3.

Table 3. Correlation of attachment dimensions with eating disorder symptoms in eating disorder patients and sine morbo individuals

\begin{tabular}{|c|c|c|c|c|c|c|c|c|c|}
\hline & Variable & $\begin{array}{l}\text { Drive for } \\
\text { thinness } \\
\text { (EDI) }\end{array}$ & $\begin{array}{l}\text { Body } \\
\text { dissatisfaction } \\
\text { (EDI) }\end{array}$ & $\begin{array}{l}\text { Bulimia } \\
\text { (EDI) }\end{array}$ & $\begin{array}{l}\text { Emotional } \\
\text { eating } \\
\text { (TFEQ-R21) }\end{array}$ & $\begin{array}{l}\text { Binges } \\
\text { (EBSS) }\end{array}$ & $\begin{array}{l}\text { Dieting } \\
\text { (EBSS) }\end{array}$ & $\begin{array}{l}\text { Exercise } \\
\text { for } \\
\text { weight } \\
\text { loss } \\
\text { (EBSS) }\end{array}$ & $\begin{array}{l}\text { Purging } \\
\text { (EBSS) }\end{array}$ \\
\hline \multirow[t]{8}{*}{ SM } & $\begin{array}{l}\text { Secure } \\
\text { attachment }\end{array}$ & $-.45^{* * *}$ & $-.26^{*}$ & $-.37^{* *}$ & -.15 & $-.45^{* * *}$ & $-.36^{* *}$ & $-.29^{*}$ & -.09 \\
\hline & $\begin{array}{l}\text { Fearful } \\
\text { attachment }\end{array}$ & $.34^{* *}$ & $.27^{*}$ & $.28^{*}$ & .07 & $.28^{*}$ & .17 & .14 & -.03 \\
\hline & $\begin{array}{l}\text { Preoccupied } \\
\text { attachment }\end{array}$ & $.26^{*}$ & .23 & .17 & $.28^{*}$ & .20 & .15 & -.08 & .16 \\
\hline & $\begin{array}{l}\text { Dismissive } \\
\text { attachment }\end{array}$ & .04 & .04 & -.06 & -.13 & -.16 & -.01 & $.39^{* * * *}$ & .07 \\
\hline & Maternal care & $-.25^{*}$ & -.24 & -.16 & -.23 & -.10 & $-.29^{*}$ & -.10 & -.09 \\
\hline & Paternal care & -.08 & -.11 & -.08 & -.16 & .02 & -.19 & -.08 & -.02 \\
\hline & $\begin{array}{l}\text { Maternal } \\
\text { overprotection }\end{array}$ & -.01 & -.09 & .08 & -.07 & .01 & .05 & .08 & -.08 \\
\hline & $\begin{array}{l}\text { Paternal } \\
\text { overprotection }\end{array}$ & .04 & .00 & .18 & .04 & .07 & $.24^{+}$ & .01 & -.02 \\
\hline \multirow[t]{8}{*}{ ED } & $\begin{array}{l}\text { Secure } \\
\text { attachment }\end{array}$ & -.17 & -.15 & -.02 & -.03 & .07 & -.15 & -.19 & .01 \\
\hline & $\begin{array}{l}\text { Fearful } \\
\text { attachment }\end{array}$ & $.26^{*}$ & .06 & .23 & $.26^{*}$ & $.25^{*}$ & .04 & .12 & $.27^{*}$ \\
\hline & $\begin{array}{l}\text { Preoccupied } \\
\text { attachment }\end{array}$ & .09 & .04 & $.21^{+}$ & .15 & .07 & .02 & .12 & .04 \\
\hline & $\begin{array}{l}\text { Dismissive } \\
\text { attachment }\end{array}$ & .19 & -.04 & .18 & .16 & .20 & .08 & .14 & $.21^{+}$ \\
\hline & Maternal care & -.13 & .06 & $-.38^{* * * *}$ & $-.26^{*}$ & $-.27^{*}$ & $-.21^{+}$ & .13 & $-.37^{* *}$ \\
\hline & Paternal care & -.15 & -.09 & $-.37^{* *}$ & $-.32^{* *}$ & $-.35^{* *}$ & -.05 & .08 & $-.32^{* *}$ \\
\hline & $\begin{array}{l}\text { Maternal } \\
\text { overprotection }\end{array}$ & -.09 & -.18 & -.07 & -.02 & -.14 & .19 & -.05 & -.17 \\
\hline & $\begin{array}{l}\text { Paternal } \\
\text { overprotection }\end{array}$ & .09 & -.09 & .10 & $.29^{*}$ & .11 & .06 & -.08 & -.11 \\
\hline
\end{tabular}

Note. $N$ eating disorder $=67, N$ sine morbo $=67$. SM: sine morbo group, ED: eating disorder group. Spearman's rank correlation coefficients are indicated. ${ }^{+} p<.10 . * p<.05 . * * p<.01 . * * * p<.001$.

Apparent differences could be observed between the correlation patterns of the two groups. As age is overall important in both attachment and EDs - and the ED group was younger - partial correlations were conducted with adjustment for age. According to Fisher's z' transformation, significant differences were found between the groups' correlation coefficients in the relationships between secure attachment and bulimia $(\mathrm{Z}=-2.083, p=.037)$, secure attachment and purging $(\mathrm{Z}=-3.136, p=.002)$, dismissive attachment and purging $(\mathrm{Z}=-2.099, p=.036)$, maternal care and exercises for weight loss $(Z=-2.609 ; p=.009)$, and paternal care and purging $(Z=2.071, p=.038)$. Tendency-level differences were found in the relationships between secure attachment and drive for thinness $(Z=-1.777, p=.076)$, dismissive 
attachment and emotional eating $(Z=-1.935, p=.053)$, and dismissive attachment and exercises $(Z=1.744, p=.081)$.

To test the predictors of EDs, a hierarchical multiple binary logistic regression analysis was conducted with enter method. In the first model, those attachment dimensions were involved, which were significantly different between the two groups according to the bivariate analyses - namely, dimensions of secure, fearful and preoccupied attachment (Table 1). According to these results, only the lower degree of adult attachment security was a significant predictor of higher odds for diagnosed EDs. Attachment quality explained 22.4\% of the variance. The second model was adjusted for age and the level of depression. Lower adult atachment security still remained a significant predictor of EDs. Younger age of participants was also a significant predictor of EDs, and higher levels of depression increased their odds at a tendency-level. These three variables explained $36.6 \%$ of the variance of EDs. Results are detailed in Table 4.

Table 4. Predictors of eating disorders

\begin{tabular}{|c|c|c|c|c|}
\hline & & Eating & & \\
\hline & Predictor & $\mathrm{p}$ & $\begin{array}{l}\text { OR } \\
95 \% \mathrm{CI} \\
L L U L\end{array}$ & Nagelkerke $\mathrm{R}^{2}$ \\
\hline Model 1 & Attachment security (RSQ) & $.003^{* 7 ?}$ & $\begin{array}{l}0.46 \\
0.27,0.76\end{array}$ & .224 \\
\hline & Dismissive attachment (RSQ) & .501 & $\begin{array}{l}1.16 \\
0.76,1.76\end{array}$ & \\
\hline & Fearful attachment (RSQ) & .370 & $\begin{array}{l}1.23 \\
0.78,1.94\end{array}$ & \\
\hline Model 2 & Attachment security (RSQ) & $.030^{*}$ & $\begin{array}{l}0.54 \\
0.31,0.94\end{array}$ & .366 \\
\hline & Dismissive attachment (RSQ) & .342 & $\begin{array}{l}1.08 \\
0.67,1.75\end{array}$ & \\
\hline & Fearful attachment (RSQ) & .898 & $\begin{array}{l}1.03 \\
0.63,1.69\end{array}$ & \\
\hline & Age & $.001^{* *}$ & $\begin{array}{l}0.93 \\
0.89,0.97\end{array}$ & \\
\hline & Depression (CES-D) & $.076^{+}$ & $\begin{array}{l}1.04 \\
1.00,1.08\end{array}$ & \\
\hline
\end{tabular}

Note. $N$ ED group $=67, N$ SM group $=67 . * \mathrm{DSM}-\mathrm{V}$ diagnoses of anorexia nervosa, bulimia nervosa, binge eating disorder, or eating disorder not otherwise specified. $\mathrm{OR}=$ odds ratio $(\exp \beta) ; \mathrm{CI}=$ confidence interval; $L L=$ lower limit; $U L=$ upper limit. ${ }^{+} p<.10{ }^{*} p<.05 . * * p<.01 . * * * p<.001$.

\section{Discussion}

\subsection{Characteristics of Sine Morbo Individuals}

More than $70 \%$ SM group dieted or exercised at least monthly in order to reduce weight, suggesting that young women are gradually showing an increase in approval of diet and exercise activities oriented towards weight and body shape modification (Grogan, 2007). Although weekly binges are only one of the major criteria of BED (APA, 2013), and binges are gradually increasing maladaptive eating behaviors (Gearhardt et al., 2012), their 12\% frequency in the SM group is far higher than the lifetime prevalence (0.8-1.9\%) of BED (Kessler et al., 2013), especially as participants with an ED history and significant bulimic symptoms were excluded from the SM group. A methodological reason for this can be the self-selection bias of voluntary online surveys, so characteristics of individuals who are more concerned with eating disturbances than the general population may be overrepresented in the present results (Betlehem, 2010). Furthermore, data on binges were self-reported in cases of SM participants, and subjective binges may differ from objective ones (Niego et al., 1997). The increasing emphasis on weight, shape and eating control can contribute to the sensitivity about the quantity of food eaten, and thus to a more negative judgement of one's own eating behavior (Johnson \& Wardle, 2005).

Regarding attachment features, the SM group more frequently had secure adult attachment patterns than the ED group, and the degree of attachment security was statistically much higher in the SM group; which is in correspondence with previous evidences (Latzer et al., 2002; Orzolek-Kronner, 2002; Ward et al., 2000, Zachrisson \& Skårderud, 2010). The distribution of secure and insecure adult attachment patterns was almost the same on a representative Hungarian adult sample (Susánszky \& Szántó, 2013).

Higher adult attachment preoccupation in the SM group was related to stronger tendencies for emotional eating. Adult attachment preoccupation is characterized by high anxiety, ambivalence, dependence and repressed anger and fear of losing the object (Sable, 2008). Individuals with preoccupied attachment generally engage in emotional and behavioral hyper-activation under distress resulting in stronger negative thoughts, moods, emotion dysregulation, and maladaptive coping mechanisms (Mikulincer et al., 2003; Van Durme et al., 2015). Since emotional eating can be viewed as a 
maladaptive attempt to reduce negative emotions (Czeglédi \& Urbán, 2010) results can be explained through the impact of attachment on emotion regulation. Eating can regulate emotions and emotions may influence eating through (a) emotional food choice; (b) emotional suppression of food intake; (c) dysfunctions of eating control; (d) eating to regulate emotions; and (e) emotion-congruent modulation of eating (Macht, 2008). Present results confirm that SM individuals with stronger attachment preoccupation have a higher tendency to engage in emotional eating as a maladaptive coping with their emotional and interpersonal difficulties. This suggests at least taking potential attachment concerns such as ambivalence, separation anxiety, suppressed fury or dependence with the primary object into account, when investigating the personal precipitating or maintaining factors of emotional eating in SM indi viduals. Highlighting attachment-driven irrational thoughts, counteracting primary tendencies for hyper-activation and seeking for more adaptive ways of coping with negative moods may hold therapeutic potentials (Szalai, 2016).

The severity of drive for thinness, body dissatisfaction, bulimia, and binge and purge symptoms were related to the degree of attachment insecurity in the SM group, which is in line with previous studies that evidenced the association between lower attachment security and stronger ED symptoms (Broberg et al., 2001) dysfunctional eating attitudes and behaviors, and an increased risk of EDs (Milan \& Acker, 2014). The stronger association between ED symptoms and adult attachment dimensions then parental bonding features in SM individuals may suggest that SM adults consider their partner or close peer relationships as primary attachments rather than their parents. This may implicate a bigger influence of peer attachments on the mental health of SM individuals than parental bonds; which opens a gap of research to be furthered by comparative studies and metaanalyses.

\subsection{Characteristics of Eating Disorder Patients}

Approximately $78 \%$ of the ED patients dieted or exercised at least monthly in order to reduce weight. Body image disorder is and body dissatisfaction are well-known characteristics of classic eating disorders (APA, 2013, Stice, 2002), which lead to an increased desire for altering the bodily appearance, particularly weight and shape (Fairburn et al., 2003). As diet and exercise are regular weight and body shape modification strategies (Grogan, 2007), the high prevalence corresponds with the natural characteristics of such a heterogeneous ED sample, just as the presence of at least weekly frequent binges in almost $50 \%$.

With regard to the attachment characteristics of the ED group, the frequency of secure adult attachment patterns was significantly lower than in the SM group, and ED patients more often had fearful and preoccupied patterns; however, the frequency of dismissive attachment patterns was only marginally different. The degree of attachment security was statistically much lower in the ED group, with a moderate difference in the degree of adult attachment preoccupation, and a small difference in the degree of fearfulness between the SM and ED groups. Many studies confirmed the lower attachment security of ED patients, and revealed almost the same prevalence ( $83.6 \%$ vs. $86.4 \%$ ) of insecure attachment types on this sample (Münch et al., 2016; O'Shaughnessy, \& Dallos, 2009). Some studies also pointed out the relationship between predominantly preoccupied or fearful attachment patterns and ED symptomology (Suldo \& Sandberg, 2000; Troisi et al., 2005). Friedberg and Lyddon (1996) concluded that the degree of attachment security and preoccupation can discriminate between SM and ED individuals; however, other studies linked dismissive attachment with EDs (e.g., Eggert et al., 2007).

Certainly, findings regarding attachment characteristics of ED patients may depend on the composition of the sample including diagnostic subtypes and the type of symptoms (Illing et al., 2010). As dismissive attachment is predominantly found in anorexia nervosa and bulimia nervosa or BED mostly preoccupied or fearful patterns can be observed (Ringer \& Crittenden, 2007; Zachrisson \& Skårderud, 2010) results may be grounded by the predominance of binge and bulimic patients in this sample. On the other hand, negative self-esteem is a central maintaining factor in each ED (Fairburn et al., 2003), and both preoccupied and fearful attachment patterns are characterized by a negati ve image of the self (Sable et al., 2008). Maladaptive effects of hyperactive emotion regulation - a major link between disturbed attachment and EDs-are also often present in preoccupied or fearful attachment patterns (Mikulincer et al., 2003; Van Durme et al., 2015). Sociocultural factors can also be contributory, since in another representative Hungarian sample detachment was unrelated to the risk of EDs (Szalai \& Czeglédi, 2015). These associations support the marginal difference in dismissal between groups, and suggest that attachment anxiety, preoccupation with relationships and fear in self- and object-relations were related to ED symptoms in this sample rather than the degree of attachment dismissal. Thus, the first hypothesis proposing that insecure adult attachment types would be more frequent in ED patients than in SM individuals can be partially supported.

Associations were also evidenced between higher adult attachment fearfulness and lower maternal and paternal care of ED patients and their stronger tendencies for emotional eating. Individuals with fearful attachment often suffered from traumatic life events, lack of acceptance, and are often featured by both strong anxiety and avoidance in close relationships, resulting in distrustfulness, disorganized interpersonal behavior (Beeney et al., 2015; Dozier et al, 2008). 
This can lead to higher tendencies for impulsivity and aggression coupled with impaired social conflict solution skills and worse emotion regulation (Fossati et al., 2005; Mikulincer et al., 2003). In line with these dysfunctions, Hernandez-Hons and Wooley (2011) evidenced attachment concerns among the most important themes related to emotional eating, including (a) relationship history; (b) degree of acceptance; (c) addiction as a coping mechanism for insecure attachment; and (d) emotional eating as reminiscent of ambivalent attachment. In correspondence with present results, more insecure, less accepting and ambivalent parental attachment also predicted high-calorie food consumption (Faber \& Dubé, 2015), which was directly related to the degree of emotional eating; suggesting that at least in part maladaptive coping circles with insecure attachment can be suspected in the background of emotional eating (Hernandez-Hons \& Wooley, 2011).

Since mood intolerance and interpersonal difficulties are among the most important maintaining factors of ED symptoms (Fairburn, 2003) results can support introducing new attachment-based, relationship-focused interventions also against emotional eating. This may include fostering the availability of attachment objects, enhancing the degree of parental care and counteracting adult attachment fearfulness such as reducing distrustfulness and avoidance, seeking for more adaptive means of coping with distress as well as improving images of both the self and significant others. Intervention-based studies are required to confirm these intervention points and to test whether decreasing the tendencies for emotional eating would hold preventive potentials against developing more severe eating symptomology including diagnosed EDs.

In contrast with SM individuals, the degree of attachment insecurity was not related to the symptom severity in the ED group, but aspects of parental bonding were related to symptom severity predominantly in the ED group; so the second hypothesis can be only partly supported. The apparent differences in correlation patterns of attachment dimensions and ED symptoms between the two groups offer an interesting scope of interpretation. A methodological explanation of the diverse associations between aspects of parental and adult attachment and ED symptomology in the groups can be partly the lower age of the ED patients. Furthermore, the different marital statuses of the groups can also influence who are considered primary objects. It can be suspected that a considerable percentage of ED patients still identify their parents as primary attachment objects, perhaps due to social anxiety or fear of intimacy (Cash et al., 2004).

In line with this, a tendency-level stronger positive relationship was found between maternal overprotection and increased ED symptoms in the ED group than in SM individuals. The relationship between poor maternal bonding and ED symptoms is well-evidenced (Claydon et al., 2016; Ward et al., 2000). Maternal attachment disturbances are related to negative affectivity, and generally a more anxious, angry or intrusive parenting style (Adam et al., 2004), which may contribute to the ambivalence and separation-individuation problems of ED patients (Latzer et al., 2002). Overprotection and an enmeshed mother-daughter relationship are well-known traits of families affected by EDs (Minuchin et al., 2009). A lower degree of parental care was also associated with more severe symptoms in the ED group. In line with this, lower parental care and higher parental control can be associated with worse personality traits and psychological functioning and stronger ED symptoms (Amianto et al., 2015). Although more studies focus on the mother-child relationship in ED patients (Claydon et al., 2016; Pace et al., 2015), present results also underline the association between the degree of paternal care and the severity of ED symptoms among ED patients. Similarly, Horesh et al. (2015) found that patients with overprotective or avoidant paternal bonding presented higher levels of depression and worse eating and body shape concerns (including more severe food-restraint) than those who experienced caring and benevolent father-daughter relationships.

As there was no difference in the degree of reported parental care between the two groups, but a lower degree of parental care associated with increased ED symptoms in the ED group, it is likely that ED patients require more attention and emotional support from their parents (Latzer et al., 2002; Orzolek-Kronner, 2002) than SM indi viduals. In line with this suggestion, ED patients suffer from separation anxiety (Troisi et al., 2005) and ED symptoms usually engage parental involvement, decreasing the distance with their parents (Orzolek-Kronner, 2002). Mothers of anorexic females reported themselves low levels of alexithymia, while their daughters perceived high maternal alexithymia (Pace et al., 2015). This hints at the differences in the perception of the degree of emotional responsiveness in ED families. Attachment patterns underlie one's command on autonomy, intimacy and reinforcement (Sable et al., 2008); thus, attachment characteristics may contribute to different assumptions of parental care. As affectively supportive parenting is negatively associated with weight and dieting preoccupation, bulimic behaviors, and most EDI scales, hidden needs for parental care might be crucial for some ED patients. Enhancing an autonomy-fostering, emotionally caring parental attachment can be an important coping mechanism against ED symptoms (Kenny \& Hart, 1992), because family members are the patient's and the therapist's best allies and most important resources for (Bulik, 2014).

\subsection{Attachment and Eating Disorder Symptomology}

From all attachment dimensions, only lower adult attachment security was a significant predictor of diagnosed EDs, 
with adjustment for age and the le vel of depression. These variables explained $36.6 \%$ of the variance of EDs. Secure attachment supports good mental health and stable self-structure (Oliviera \& Costa, 2009), but attachment insecurity is associated with poor self-concept, identity and self-esteem, increased stress sensitivity, anxiety, and more negative emotions, and with impaired recognition of hunger and satiety (Gander et al., 2015; Lee \& Hankin, 2009, Maunder \& Hunter, 2008; Tasca et al., 2009a). Effects of attachment disturbances on emotion dysregulation including hyper-activation or deactivation of emotions can also contribute to this result (Ty \& Francis, 2013; Van Durme et al., 2015). Furthermore, insecure attachment negatively influences body satisfaction with adjustment for age and BMI both in SM and ED populations (Cash at al., 2004; Gander et al., 2015; Keating et al., 2013), which can contribute to precipitating or maintaining the ED (Fairburn et al., 2003).

In this model, younger age significantly increased the odds for diagnosed EDs, and higher depression contributed to them on a tendency-level. Younger age is an evidenced risk factor for ED symptoms (Hudson et al., 2007), as aging decreases the importance of appearance in favor of greater self-acceptance (Tiggemann, 2004). Attachment characteristics may also change with age (Pinquart et al., 2013); thus, the age difference of the groups could also contribute to the differences found between the SM and ED indi viduals. Generally, higher levels of depression are found in most eating pathologies (Stice et al., 2002), and there is a high comorbidity between eating and mood disorders (Tasca et al., 2009a). Depressive thinking can attack various aspects of self-acceptance (Olivardia et al., 2004) including the satisfaction with bodily appearance (McCabe et al., 2001). Therefore, depressive symptoms can contribute to the development of EDs (Polivy \& Herman, 2002), increasing the incidents of EDs by almost three-fold in one study that took place over a period of eight years (Stice et al., 2011). Negative affections can also predict the maintenance of eating pathology (Stice, 2002), supporting present results.

As ED symptomology can be interpreted through a multicausal etiology built on complex interactions of predisposing, precipitating and maintaining factors (Jansen, 2001), the above described relationships suggest several direct and indirect paths between lower attachment security and the increased odds of EDs (Tasca et al., 2009a). Firstly, early experiences, traumas and parenting quality can be related to EDs through the mediation of adolescent and adult attachment characteristics (Tasca et al., 2011). Secondly, since personality and family traits are central in ED's (Minuchin et al., 2009; Tasca et al., 2011), and attachment features contribute to both the ego functioning and object relations (Dozier et al., 2008), the role of attachment in patients with eating disorders may be viewed as a system mediating between intrapersonal experience and interpersonal actions that serve to maintain the symptoms.. Thirdly, both attachment anxiety and avoidance can be directly related to the increased risk of ED symptoms (e.g., Szalai \& Czeglédi, 2015; Tasca \& Balfour, 2014). Lastly, longitudinal studies evidenced that the role of attachment in EDs can be considered an important background variable, as its quality moderated the relationship between ED risk factors and later disordered eating attitudes and behaviors (Milan \& Acker, 2014). The maturation of the self is interwoven with attachment functioning, so attachment dysfunctions can contribute to self-disturbances, and on the basis of disturbed neurobiological functioning, deficient self-functioning can be linked to ED symptomology (Amianto et al., 2015). Attachment insecurity and disorganization can interact with genetic and environmental vulnerabilities, and serve as a general risk factor for adult psychopathology including borderline personality disorder and bulimic symptoms (Dozier et al., 2008; Steele \& Shiever, 2010). Therefore, deficient attachment functioning may be particularly important in those ED patients who suffer emotion-processing deficits or personality disorders; accordingly, these patients respond less well to exclusively symptom-focused therapies (Myers et al., 2006; Tasca et al., 2011).

Attachment quality can be related to EDs through various paths Koskina \& Giovizolias, 2010) including a) the mediation of self-concept (Illing et al., 2010), self-worth, and self-acceptance (Gander et al., 2015); b) body dissatisfaction (Keating et. al., 2013); c) the extent of perfectionism (Dakanalis et al., 2014); d) as well as mood and mood-regulation disorders such as emotional instability (Münch et al., 2016), alexithymia (Tasca et al., 2011), higher level of depression (Tasca et al., 2009a), and emotion-dysregulation (Ty \& Francis, 2013) including the hyperactivation or deactivation of emotions (Tasca et al., 2009a). Effects of attachment characteristics on emotion-regulation are also observable on the level of autonomous functioning. Attachment insecurity is related to higher autonomous reactivity, while attachment security can offer better psychophysiological responses to interpersonal challenges in EDs (Dias et al., 2011). Furthermore, when attachment anxiety can be decreased through an ED treatment, outcomes may be better (Tasca et al., 2011; Tasca \& Balfour, 2014) that supports the association between higher attachment security lower level of ED symptoms. These associations suggest insecure attachment is a general, indirect risk factor for EDs, and attachment security can be a protective factor against ED symptomology, supporting the third hypothesis proposed in this paper.

\section{Limitations}

Limitations should be taken into account when interpreting results. Anthropometric data were self-reported, which can impair validity. The cross-sectional study design does not allow us to draw cause and effect conclusions. The 
convenience sampling method and voluntary participation cannot exclude the self-selection bias that may modify the features of the sample. Although the lack of non-response rates is a general feature of online surveys, it can limit the generalizability of our findings. As some aspects of attachment are outside of awareness, self-report measures may hold a susceptible bias in responses (Steele \& Shiever, 2010). Non-response rates are not available from the SM group; however, according to clinician reports, on average only $30 \%$ of the invited patients filled out the online survey. Although many significant relationships were found, they had generally statistically low effect size. Similar to other studies (e.g. Bäackström \& Holmes, 2001; Ravitz et al., 2010), internal consistencies of the RSQ were low or moderate, which may limit the reliability of the results. Only a few associations with low effect sizes were found between dysfunctional attachment and emotional eating, and overweight emotional eaters were directly excluded from the sample because of their low numbers $(N=14)$ possibly distorting results. The role of paternal attachment in eating symptomology could be an exceptional direction to be explored in further studies. As attachment security with adjustment for age and the level of depression explained a moderate part of the variance of EDs, we emphasize that their symptomology is more complex than it could be explained through attachment disturbances only.

\section{Conclusions and Treatment Implications}

Present results from this study highlight that ED patients generally have more dysfunctional attachment patterns than SM indi viduals, with highly different relationship patterns between aspects of attachment and ED symptoms than in SM individuals, suggesting a complex interplay between dimensions of dysfunctional attachment patterns and intensive ED symptomology. In this sample, attachment insecurity, preoccupation with relationships and fears in self- and object-relations were related to ED symptomology rather than dismissive traits. In those emotional eaters who complain about relationship stressors, attachment disturbances should be assessed and the adaptive relationships and interpersonal coping mechanisms should be facilitated. In contrast with overweight emotional eaters, underweight individuals under-eat in response to negative moods (Geliebter \& Aversa, 2003). This finding can offer a novel scope of research regarding the possible relationship between dismissive attachment and emotion deactivation and restricted eating in underweight individuals experiencing negative moods. As attachment dimensions can play a role in different perceptions of parental responsiveness, unmet needs of parental care can be an important concern for certain ED patients. Lower attachment security was a predictor of diagnosed EDs and is also related with the intensity of eating behavior severity in SM individuals, supporting that secure attachment can be a protective factor against EDs.

Therefore, attachment functioning should be assessed with special attention on dimensions of insecurity, preoccupation or fearfulness in individuals who complain about both maladaptive eating behaviors and relationship stressors. On the basis of these assessments, a combination of a categorical diagnosis and a dimensional description of the patient's personality and attachment functioning can be suggested in order to build a better understanding of the personal ED symptomology, appropriate treatments, and to promote good therapeutic alliance (Illing et al., 2010; Tasca et al., 2009b; Tasca \& Balfour, 2014). Since the degree of attachment security is associated with ED symptomology, an attachment-sensitive can be beneficial for certain ED patients (Amianto et al., 2016; Tasca \& Balfour, 2014).

Attachment interventions in ED treatment should support four key areas (Amianto et al., 2016; Faber \& Dubé, 2015; Keating et al., 2013; Kuipers et al., 2016; Maxwell et al., 2014; Tasca et al., 2009a, b, 2011, 2013; Tasca \& Balfour, 2014):

1. Improving the attachment-driven self-concept, with increasing self-acceptance, coherence of mind and the number of positive self-domains.

2. Improving interpersonal functioning through the modification of sensitive, dependent or avoidant interpersonal styles, fostering the availability of the attachment figure, and developing mutual trust, flexible communication, and emotional warmth in relationships.

3. Enhancing patients' reflective functions, including the capacity to reflect on themselves and significant others, especially in times of severe distress.

4. Balancing patients' low and intensive moods by improving frustration tolerance as well as coping skills for negative moods, fostering emotion recognition, and counteracting the hyper-activation or deactivation of emotions with personalized mood-regulation strategies that can lead to a more optimal intra/ interpersonal life.

Enhancing parental care and adult attachment security may be important factors against the development and the maintenance of ED symptoms. However, longitudinal studies that assess the efficacy of randomized, controlled attachment-based treatment procedures and attachment-based preventative programs are required to confirm these results. 


\section{Abbreviations}

BED: binge eating disorder

BMI: body mass index

EBSS: Eating Behavior Severity Scale

CES-D: Center for Epidemiologic Studies Depression Scale

ED: eating disorder

EDI: Eating Disorder Inventory

PBI: Parental Bonding Instrument

RSQ: Relationship Scales Questionnaire

SM: sine morbo

TFEQ-R21: Three-Factor Eating Questionnaire - Revised 21-items

\section{Acknowledgements}

TDSz was supported by the scholarship of the ÚNKP-16-3 new national excellence program of the Ministry of Human Capacities in Hungary. ECz received no financial support. Ethical approval to this non-invasive, questionnaire-based survey was given by the Medical Research Council Scientific and Research Committee (5692-2/2015/EKU). Informed consent was obtained from all respondents before the participation and filling out the survey. All procedures followed were in accordance with ethical standards of the responsible committee on human experimentation and with the Helsinki Declaration. The authors declare no conflicts of interest. The dataset on which the results and conclusions rely is available from the correspondent author.

\section{References}

Adam, E. K., Gunnar, M. R., \& Tanaka, A. (2004). Adult attachment, parent emotion, and observed parenting behavior: Mediator and moderator models. Child Development, 75(1), 110-122. https://doi.org/10.1111/j.1467-8624.2004.00657.x

Ainsworth, M. D. S. (1989). Attachments beyond infancy. American Psychology, 44(4), 709-716. https://doi.org/10.1037/0003-066X.44.4.709

American Psychiatric Association. APA. (2013). Diagnostic and statistical manual of mental disorders - Fifth edition. DSM-V. Arlington: American Psychiatric Publishing. https://doi.org/10.1176/appi.books.9780890425596

Amianto, F., Ercole, R., Abbate Daga, G., \& Fassino, S. (2015). Exploring Parental Bonding in BED and Non - BED Obesity Compared with Healthy Controls: Clinical, Personality and Psychopathology Correlates. European Eating Disorders Review, 24(3), 187-196. https://doi.org/10.1002/erv.2419

Amianto, F., Northoff, G., Abbate Daga, G., Fassino, S., \& Tasca, G. (2016). Is anorexia nervosa a disorder of the self? A psychological approach. Frontiers in Psychology, 7, 849. https://doi.org/10.3389/fpsyg.2016.00849

Anglé, S., Engblom, J., Eriksson, T., Kautiainen, S., Saha, M. T., Lindfors, P., \& Rimpelä, A. (2009). Three factor eating questionnaire-R18 as a measure of cognitive restraint, uncontrolled eating and emotional eating in a sample of young Finnish females. International Journal of Behavioral Nutrition and Physical Activity, 6(1). https://doi.org/10.1186/1479-5868-6-41

Bäackström, M., \& Holmes, B. M. (2001). Measuring adult attachment: A construct validation of two self-report instruments. Scandinavian Journal of Psychology, 42(1), 79-86. https://doi.org/10.1111/1467-9450.00216

Beeney, J. E., Stepp, S. D., Hallquist, M. N., Scott, L. N., Wright, A. G., Ellison, W. D., \& Pilkonis, P. A. (2015). Attachment and social cognition in borderline personality disorder: Specificity in relation to antisocial and avoidant personality disorders. Personality Disorders: Theory, Research, and Treatment, 6(3), 207-215. https://doi.org/10.1037/per0000110

Betlehem, J. J. (2010). Selection bias in web surveys. International Statistical Review,78(2), 161-188. https://doi.org/10.1111/j.1751-5823.2010.00112.x

Bowlby, J. (1977). The making and breaking of affectional bonds. II. Some principles of psychotherapy. The fiftieth Maudsley Lecture. The British Journal of Psychiatry, 130(5), 421-431. https://doi.org/10.1192/bjp.130.5.421

Broberg, A. G., Hjalmers, I., \& Nevonen, L. (2001). Eating disorders, attachment and interpersonal difficulties: a comparison between 18 - to 24 - year - old patients and normal controls. European Eating Disorders Review, 9(6), 
381-396. https://doi.org/10.1002/erv.421

Buist, K. L., Dekovic, M., Meeus, W., \& van Aken, M. A. G. (2002). Developmental patterns in adolescent attachment to mother, father and sibling. Journal of Youth and Adolescence, 31(3), 167-176.

https://doi.org/10.1023/A:1015074701280

Bulik, C. M. (2014). 9 Eating Disorders Myths Busted. Academy For Eating Disorders: National Institute of Mental Health Alliance for Research Progress meeting. Retreived from http://www.aedweb.org/index.php/10-news/171-9-truths-about-eating-disorders Accessed: 30 Oct 2016.

Cash, T. F., Thériault, J., \& Annis, N. M. (2004). Body image in an interpersonal context: Adult attachment, fear of intimacy and social anxiety. Journal of Social and Clinical Psychology,23(1), 89-103. https://doi.org/10.1521/jscp.23.1.89.26987

Claydon, E., Zerwas, S., Callinan, L., \& Smith, M. (2016). Parental reflective functioning among mothers with eating disorder symptomatology. Eating Behaviors, 14(23), 141-144. https://doi.org/10.1016/j.eatbeh.2016.09.002

Cohen, J. (1988). Statistical power analysis for the behavioral sciences (Second edition). New Jersey: Lawrence Erlbaum.

Cole-Detke, H., \& Kobak, R. (1996). Attachment processes in eating disorder and depression. Journal of Consulting and Clinical Psychology, 64(2), 282-290. https://doi.org/10.1037/0022-006X.64.2.282

Czeglédi, E., \& Urbán, R. (2010). A háromfaktoros evési kérdőív (Three Factor Eating Questionnaire Revised 21-item) hazai adaptációja. [Hungarian adaptation of the Three Factor Eating Questionnaire Revised 21-item.] Hungarian Journal of Psychology, 65(3), 463-494. https://doi.org/10.1556/MPSzle.65.2010.3.2

Dakanalis, A., Timko, C. A., Zanetti, M. A., Rinaldi, L., Prunas, A., Carrà, G., \& Clerici, M. (2014). Attachment insecurities, maladaptive perfectionism, and eating disorder symptoms: Alatent mediated and moderated structural equation modeling analysis across diagnostic groups. Psychiatry Research, 215(1), 176-184. https://doi.org/10.1016/j.psychres.2013.10.039

Demetrovics, Zs. (2007). Drog, család, személyiség. Különbözö típusú drogok használatának személyiségpszichológiai és családi háttere. [Drugs, family, personality: the psychological backg round of the individual and the family in the use of various types of drugs.] Budapest: L'Harmattan.

Dias, P., Soares, I., Klein, J., Cunha, J. P., \& Roisman, G. I. (2011). Autonomic correlates of attachment insecurity in a sample of women with eating disorders. Attachment \& Human Development, 13(2), 155-167. https://doi.org/10.1080/14616734.2011.554005

Dozier, M., Stovall-McClough, K. C., \& Albus, K. E. (2008). Attachment and psychopathology in adulthood. In J. Cassidy \& P. R. Shaver, (Eds.), Handbook of attachment: Theory, research, and clinical applications, 2nd ed. (pp. 718-744). New York: Guilford Press.

Eggert, J., Levendosky, A., \& Klump, K. (2007). Relationships among attachment styles, personality characteristics, and disordered eating. International Journal of Eating Disorders, 40(2), 149-155. https://doi.org/10.1002/eat.20351

Elgin, J., \& Pritchard, M. (2006). Adult attachment and disordered eating in undergraduate men and women. Journal of College Student Psychotherapy, 21(2), 25-40. https://doi.org/10.1300/J035v21n02_05

Faber, A., \& Dubé, L. (2015). Parental attachment insecurity predicts child and adult high-caloric food consumption. Journal of Health Psychology, 20(5), 511-524. https://doi.org/10.1177/1359105315573437

Fairburn, C. G., Cooper, Z., \& Shafran, R. (2003). Cognitive behaviour therapy for eating disorders: A "transdiagnostic" theory and treatment. Behaviour Research and Therapy, 41(5), 509-528. https://doi.org/10.1016/S0005-7967(02)00088-8

Fossati, A., Feeney, J. A., Carretta, I., Grazioli, F., Milesi, R., Leonardi, B., \& Maffei, C. (2005). Modeling the relationships between adult attachment patterns and borderline personality disorder: The role of impulsivity and aggressiveness. Journal of Social and Clinical Psychology, 24(4), 520-537. https://doi.org/10.1521/jscp.2005.24.4.520

Friedberg, N. L., \& Lyddon, W. J. (1996). Self-other working models and eating disorders. Journal of Cognitive Psychotherapy, 10(3), 193-202. Retreived from

http://www.ingentaconnect.com/content/springer/jcogp/1996/00000010/00000003/art00003 Accessed: 30 Oct 2016

Gander, M., Sevecke, K., \& Buchheim, A. (2015). Eating disorders in adolescence: attachment issues from a developmental perspective. Frontiers in Psychology, 6. https://doi.org/10.3389/fpsyg.2015.01136

Garner, D. M., Olmsted, M. P., \& Polivy, J. (1983). Development and validation of a multidimensional eating disorder 
inventory for anorexia nervosa and bulimia. International Journal of Eating Disorders, 1, 15-34. https://doi.org/10.1002/1098-108X(198321)2:2<15::AID-EAT2260020203>3.0.CO;2-6

Gearhardt, A. N., White, M. A., Masheb, R. M., Morgan, P. T., Crosby, R. D., \& Grilo, C. M. (2012). An examination of the food addiction construct in obese patients with binge eating disorder. International Journal of Eating Disorders, 45(5), 657-663. https://doi.org/10.1002/eat.20957

Geliebter, A., \& Aversa, A. (2003). Emotional eating in overweight, normal weight, and underweight indi viduals. Eating Behaviors, 3(4), 341-347. https://doi.org/10.1016/S1471-0153(02)00100-9

Griffin, D., \& Bartholomew, K. (1994). Models of the self and others: fundamental dimensions underlying measures of adult attachment. Journal of Personality and Social Psychology, 67(3), 430-445. https://doi.org/10.1037/0022-3514.67.3.430

Grogan, S. (2007). Body image: Understanding body dissatisfaction in men, women and children. New York: Routledge.

Hernandez - Hons, A., \& Woolley, S. R. (2012). Women's experiences with emotional eating and related attachment and sociocultural processes. Journal of Marital and Family Therapy, 38(4), 589-603. https://doi.org/10.1111/j.1752-0606.2011.00239.x

Horesh, N., Apter, A., Ishai, J. O., Danziger, Y., Miculincer, M., Stein, D., \& Minouni, M. (1996). Abnormal psychosocial situations and eating disorders in adolescence. Journal of the American Academy of Child \& Adolescent Psychiatry, 35(7), 921-927.https://doi.org/10.1097/00004583-199607000-00019

Hudson, J. I., Hiripi, E., Pope, H. G., \& Kessler, R. C. (2007). The prevalence and correlates of eating disorders in the National Comorbidity Survey Replication. Biological Psychiatry, 61(3), 348-358. https://doi.org/10.1016/j.biopsych.2006.03.040

IBM Corporation. (2015). IBM SPSS Statistics for Windows, Version 23.0. Armonk. New York: IBM Corporation.

Illing, V., Tasca, G. A., Balfour, L., \& Bissada, H. (2010). Attachment insecurity predicts eating disorder symptoms and treatment outcomes in a clinical sample of women. The Journal of Nervous and Mental Disease, 198(9), 653-659. https://doi.org/10.1097/NMD.0b013e3181ef34b2

Jansen, A. (2001). Towards effective treatment of eating disorders: nothing is as practical as a good theory. Behaviour Research and Therapy, 39(9), 1007-1022. https://doi.org/10.1016/S0005-7967(01)00010-9

Johnson, F., \& Wardle, J. (2005). Dietary restraint, body dissatisfaction, and psychological distress: a prospective analysis. Journal of Abnormal Psychology, 114(1), 119-125. https://doi.org/10.1037/0021-843X.114.1.119

Keating, L., Tasca, G. A., \& Hill, R. (2013). Structural relationships among attachment insecurity, alexithymia, and body esteem in women with eating disorders. Eating Behaviors, 14(3), 366-373. https://doi.org/10.1016/j.eatbeh.2013.06.013

Kenny, M. E., \& Hart, K. (1992). Relationship between parental attachment and eating disorders in an inpatient and a college sample. Journal of Counseling Psychology, 39(4), 521-526. https://doi.org/10.1037/0022-0167.39.4.521

Kessler, R.C., Berglund, P.A., Chiu, W.T., Deitz, A.C., Hudson, J.I., Shahly, V., \& Bruffaerts, R. (2013). The prevalence and correlates of binge eating disorder in the World Health Organization World Mental Health Surveys. Biological Psychiatry, 73(9), 904-914.https://doi.org/10.1016/j.biopsych.2012.11.020

Koskina, N., \& Giovazolias, T. (2010). The effect of attachment insecurity in the development of eating disturbances across gender: The role of body dissatisfaction. The Journal of Psychology, 144(5), 449-471. https://doi.org/10.1080/00223980.2010.496651

Kuipers, G. S., van Loenhout, Z., van der Ark, L. A., \& Bekker, M. H. (2016). Attachment insecurity, mentalization and their relation to symptoms in eating disorder patients. Attachment \& Human Development, 18(3), 250-272. https://doi.org/10.1080/14616734.2015.1136660

Latzer, Y., Hochdorf, Z., Bachar, E., \& Canetti, L. (2002). Attachment style and family functioning as discriminating factors in eating disorders. Contemporary Family Therapy, 24(4), 581-599. https://doi.org/10.1023/A:1021273129664

Lee, A., \& Hankin, B. L. (2009). Insecure attachment, dysfunctional attitudes, and low selfesteem predicting prospective symptoms of depression and anxiety during adolescence. Journal of Clinical Child \& Adolescent Psychology, 38(2), 219-231. https://doi.org/10.1080/15374410802698396

Lenkiewicz, K., Srebnicki, T., \& Bryńska, A. (2016). Mechanisms shaping the development of personality and personality disorders in children and adolescents. Psychiatria Polska,50(3), 


\section{1-629. https://doi.org/10.12740/PP/36180}

Macht, M. (2008). How emotions affect eating: a five-way model. Appetite, 50(1), 1-11. https://doi.org/10.1016/j.appet.2007.07.002

Masheb, R. M., \& Grilo, C. M. (2006). Emotional overeating and its associations with eating disorder psychopathology among overweight patients with binge eating disorder. International Journal of Eating Disorders, 39(2), 141-146. https://doi.org/10.1002/eat.20221

Maunder, R. G., \& Hunter, J. J. (2008). Attachment relationships as determinants of physical health. The Journal of the American Academy of Psychoanalysis and Dynamic Psychiatry, 36(1), 11-32. https://doi.org/10.1521/jaap.2008.36.1.11

Maxwell, H., Tasca, G. A., Ritchie, K., Balfour, L., \& Bissada, H. (2014). Change in attachment insecurity is related to improved outcomes 1-year post group therapy in women with binge eating disorder. Psychotherapy, 51(1), 57-65. https://doi.org/10.1037/a0031100

McCabe, M. P., Ricciardelli, L. A., \& Banfield, S. (2001). Body image, strategies to change muscles and weight, and puberty: Do they impact on positive and negative affect among adolescent boys and girls?. Eating Behaviors, 2(2), 129-149. https://doi.org/10.1016/S1471-0153(01)00025-3

Mikulincer, M., \& Shaver P. R. (2012). An attachment perspective on psychopathology. World Psychiatry, 11(1), 11-15. https://doi.org/10.1016/j.wpsyc.2012.01.003

Mikulincer, M., Shaver, P. R., \& Pereg, D. (2003). Attachment theory and affect regulation: The dynamics, development, and cognitive consequences of attachment-related strategies. Motivation and Emotion,27(2), 77-102. https://doi.org/10.1023/A:1024515519160

Milan, S., \& Acker, J. C. (2014). Early attachment quality moderates eating disorder risk among adolescent girls. Psychology \& Health, 29(8), 896-914. https://doi.org/10.1080/08870446.2014.896463

Minuchin, S., Rosman, B. L., \& Baker, L., (2009). Psychosomatic families: Anorexia nervosa in context. Boston: Harvard University Press.

Münch, A. L., Hunger, C., \& Schweitzer, J. (2016). An investigation of the mediating role of personality and family functioning in the association between attachment styles and eating disorder status. BMC Psychology, 4(1), 36. https://doi.org/10.1186/s40359-016-0141-4

Myers, T. C., Wonderlich, S. A., Crosby, R., Mitchell, J.E., Steffen, K. J., Smyth, J., \& Miltenberger, R. (2006). Is multi impulsive bulimia a distinct type of bulimia nervosa: psychopathology and EMA findings. International Journal of Eating Disorders, 39(8), 655-661. https://doi.org/10.1002/eat.20324

Nguyen-Michel, S. T., Unger, J. B., \& Spruijt-Metz, D. (2007). Dietary correlates of emotional eating in adolescence. Appetite, 49(2), 494-499. https://doi.org/10.1016/j.appet.2007.03.005

Niego, S.H., Pratt, E.M., \& Agras, W.S. (1997). Subjective or objective binge: Is the distinction valid? International Journal of Eating Disorders, 22(3), 291-298. https://doi.org/10.1002/(SICI)1098-108X(199711)22:3<291::AID-EAT8>3.0.CO;2-I

O'Connor, D. B., Jones, F., Conner, M., McMillan, B., \& Ferguson, E. (2008). Effects of daily hassles and eating style on eating behavior. Health Psychology, 27(S1), 20-31. https://doi.org/10.1037/0278-6133.27.1.S20

Olivardia, R., Pope, H. G., Borowiecki, J. J., \& Cohane, G. H. (2004). Biceps and body image: The relationship between muscularity and self-esteem, depression, and eating disorder symptoms. Psychology of Men and Masculinity, 5(2), 112-120. https://doi.org/10.1037/1524-9220.5.2.112

Oliviera, P., \& Costa, M.E. (2009). Interrelationships of adult attachment orientations, health status and worrying among fibromyalgia patients. Journal of Health Psychology, 14(8), 1184-1195. https://doi.org/10.1177/1359105309342471

Orzolek-Kronner, C. (2002). The effect of attachment theory in the development of eating disorders: Can symptoms be proximity-seeking? Child and Adolescent Social Work Journal, 19(6), 421-435. https://doi.org/10.1023/A:1021141612634

O'Shaughnessy, R., \& Dallos, R. (2009). Attachment research and eating disorders: A review of the literature. Clinical Child Psychology and Psychiatry, 14(4), 559-574. https://doi.org/10.1177/1359104509339082

Pace, C. S., Cavanna, D., Guiducci, V., \& Bizzi, F. (2015). When parenting fails: alexithymia and attachment states of mind in mothers of female patients with eating disorders. Frontiers in Psychology, 6. https://doi.org/10.3389/fpsyg.2015.01145 
Pace, C. S., Guiducci, V., \& Cavanna, D. (2016). Attachment in eating-disordered outpatients with and without borderline personality disorder. Journal of Health Psychology. https://doi.org/10.1177/1359105316636951

Parker, G., Tupling, H., \& Brown, L. B. (1979). A Parental Bonding Instrument. British Journal of Medical Psychology, 52(1), 1-10. https://doi.org/10.1111/j.2044-8341.1979.tb02487.x

Pinquart, M., Feußner, C., \& Ahnert, L. (2013). Meta-analytic evidence for stability in attachments from infancy to early adulthood. Attachment \& Human Development, 15(2), 189-218. https://doi.org/10.1080/14616734.2013.746257

Polivy, J., \& Herman, C. P. (2002). Causes of eating disorders. Annual Review of Psychology, 53(1), 187-213. https://doi.org/10.1146/annurev.psych.53.100901.135103

Radloff, L. S. (1977). The CES-D scale: A self-report depression scale for research in the general population. Applied Psychological Measurement, 1(3), 385-401. https://doi.org/10.1177/014662167700100306

Ravitz, P., Maunder, R., Hunter, J., Sthankiya, B., \& Lancee, W. (2010). Adult attachment measures: A 25-year review. Journal of Psychosomatic Research, 69(4), 419-432. https://doi.org/10.1016/j.jpsychores.2009.08.006

Ringer, F., \& Crittenden, P. M. (2007). Eating disorders and attachment: The effects of hidden family processes on eating disorders. European Eating Disorders Review, 15(2), 119-130. https://doi.org/10.1002/erv.761

Sable, P. (2008). What is Adult Attachment?. Clinical and Social Work Journal, 36(1), 21-30. https://doi.org/10.1007/s10615-007-0110-8

Steele, H., \& Siever, L. (2010). An attachment perspective on borderline personality disorder: Advances in geneenvironment considerations. Current Psychiatry Reports, 12(1), 61-67. https://doi.org/10.1007/s11920-009-0091-0

Stice, E. (2002). Risk and maintenance factors for eating pathology: a meta-analytic review. Psychological Bulletin, 128(5), 825-848. https://doi.org/10.1037/0033-2909.128.5.825

Stice, E., Marti, C. N., \& Durant, S. (2011). Risk factors for onset of eating disorders: Evidence of multiple risk pathways from an 8-year prospective study. Behaviour Research and Therapy, 49(10), 622-627. https://doi.org/10.1016/j.brat.2011.06.009

Suldo, S. M., \& Sandberg, D. A. (2000). Relationship between attachment styles and eating disorder symptomatology among college women. Journal of College Student Psychotherapy, 15(1), 59-73. https://doi.org/10.1300/J035v15n01_07

Susánszky, É., \& Szántó, Zs. (2013). Magyar Lelkiállapot 2013. [Hungarian mental health 2013.] Budapest: Semmelweis.

Szalai, T. D. (2016). Cognitive-behavioral and attachment interventions in the transdiagnostic treatment of bulimia nervosa and binge eating disorder. Journal of Mental Health and Psychosomatics, 17(4), 353-375. https://doi.org/10.1556/0406.17.2016.4.3

Szalai, T. D., \& Czegledi, E. (2015). Attachment as a predictor of risk for eating disorders on a representative Hungarian adult sample. Clinical Neuroscience, 68(11-12), 409-416. https://doi.org/10.18071/isz.68.409

Tasca, G. A., \& Balfour, L. (2014). Eating disorders and attachment: A contemporary psychodynamic perspective. Psychodynamic Psychiatry, 42(2), 257-276. https://doi.org/10.1521/pdps.2014.42.2.257

Tasca, G. A., Demidenko, N., Krysanski, V., Bissada, H., Illing, V., Gick, M., \& Balfour, L. (2009b). Personality dimensions among women with an eating disorder: Towards reconceptualizing DSM. European Eating Disorders Review, 17(4), 281-289. https://doi.org/10.1002/erv.938

Tasca, G. A., Ritchie, K., \& Balfour, L. (2011). Implications of attachment theory and research for the assessment and treatment of eating disorders. Psychotherapy, 48(3), 249-259. https://doi.org/10.1037/a0022423

Tasca, G. A., Ritchie, K., Demidenko, N., Balfour, L., Krysanski, V., Weekes, K., \& Bissada, H. (2013). Matching women with binge eating disorder to group treatment based on attachment anxiety: Outcomes and moderating effects. Psychotherapy Research, 23(3), 301-314. https://doi.org/10.1080/10503307.2012.717309

Tasca, G. A., Szadkowski, L., Illing, V., Trinneer, A., Grenon, R., Demidenko, N., \& Bissada, H. (2009a). Adult attachment, depression, and eating disorder symptoms: The mediating role of affect regulation strategies. Personality and Individual Differences, 47(6), 662-667. https://doi.org/10.1016/j.paid.2009.06.006

Tereno, S., Soares, I., Martins, C., Celani, M., \& Sampaio, D. (2008). Attachment styles, memories of parental rearing and therapeutic bond: A study with eating disordered patients, their parents and therapists. European Eating Disorders Review, 16(1), 49-58. https://doi.org/10.1016/j.paid.2009.06.006 
Tholin, S., Rasmussen, F., Tynelius, P., Karlsson, J. (2005): Genetic and environmental influences on eating behavior: The Swedish Young Male Twins Study. American Journal of Clinical Nutrition, 81(3), 564-569. Retrieved from http://ajcn.nutrition.org/content/81/3/564.full.pdf+html Accessed 1 November 2016.

Tiggemann, M. (2004). Body image across the adult life span: Stability and change. Body Image, 1(1), 29-41. https://doi.org/10.1016/S1740-1445(03)00002-0

Tóth, I., \& Gervai, J. (1999). Szülői Bánásmód Kérdőív(H-PBI): AParental Bonding Instrument (PBI) magyar változata. [Parental Bonding Istrument (H-PBI): The Hungarian version of the Parental Bonding Instrument (PBI)]. Hungarian Journal of Psychology, 54(4), 551-566. Retrieved from http://www.lib.pte.hu/sites/ptebtkscan/folyoiratok/2013/T\%C3\%B3th\%20-\%20Gervai\%20-\%20SZ\%C3\%9CL\%C $5 \% 90 \mathrm{I} \% 20 \mathrm{~B} \% \mathrm{C} 3 \% 81 \mathrm{~N} \% \mathrm{C} 3 \% 81 \mathrm{SM} \% \mathrm{C} 3 \% 93 \mathrm{D} \% 20 \mathrm{~K} \% \mathrm{C} 3 \% 89 \mathrm{RD} \% \mathrm{C} 5 \% 90 \% \mathrm{C} 3 \% 8 \mathrm{DV} \% 20(\mathrm{H}-\mathrm{PBI}) . \mathrm{pdf}$ Accessed 2 November 2016.

Troisi, A., Massaroni, P., \& Cuzzolaro, M. (2005). Early separation anxiety and adult attachment style in women with eating disorders. British Journal of Clinical Psychology, 44(1), 89-97. https://doi.org/10.1348/014466504X20053

Turner, S. A., Luszczynska, A., Warner, L., \& Schwarzer, R. (2010). Emotional and uncontrolled eating styles and chocolate chip cookie consumption. A controlled trial of the effects of positive mood enhancement. Appetite, 54(1), 143-149. https://doi.org/10.1016/j.appet.2009.09.020

Túry, F., \& Szabó, P. (2000). Az evési magatartás zavarai. [Disorders of eating behavior.] Budapest: Medicina.

Ty, M., \& Francis, A. J. (2013). Insecure attachment and disordered eating in women: The mediating processes of social comparison and emotion dysregulation. Eating Disorders, 21(2), 154-174. https://doi.org/10.1080/10640266.2013.761089

Van Durme, K., Braet, C., \& Goossens, L. (2015). Insecure attachment and eating pathology in early adolescence: Role of emotion regulation. The Journal of Early Adolescence, 35(1), 54-78. https://doi.org/10.1177/0272431614523130

VanderHam, T., Meulman, J.J., VanStrien, D.C., \& vanEngeland, H. (1997). Empirically based subgrouping of eating disorders in adolescents: a longitudinal perspective. British Journal of Psychiatry, 170(4), 363-368. https://doi.org/10.1192/bjp.170.4.363

Vargha, A., Torma, B. \& Bergman, L. R. (2015). ROPstat: a general statistical package useful for conducting person-oriented analyses. Journalfor Person-Oriented Research, 1(1-2), 87-98. https://doi.org/10.17505/jpor.2015.09

Ward, A., Ramsay, R., \& Treasure, J. (2000). Attachment research in eating disorders. British Journal of Medical Psychology, 73(1), 35-51.https://doi.org/10.1348/000711200160282

World Health Organization. WHO. (2000). Obesity: preventing and managing the global epidemic. World Health Organization.

Yager, J., Lands verk, J., \& Edelstein, C. K. (1987). A20-Month Follow-Up Study of 628 Women. American Journal of Psychiatry, 144(9), 1172-1177. https://doi.org/10.1176/ajp.144.9.1172

Zachrisson, H. D., \& Skårderud, F. (2010). Feelings of insecurity: Review of attachment and eating disorders. European Eating Disorders Review, 18(2), 97-106. https://doi.org/10.1002/erv.999

\section{Copyrights}

Copyright for this article is retained by the author(s), with first publication rights granted to the journal.

This is an open-access article distributed under the terms and conditions of the Creative Commons Attribution license which permits unrestricted use, distribution, and reproduction in any medium, provided the original work is properly cited. 